\title{
Concurrent chemotherapy (carboplatin, paclitaxel, etoposide) and involved-field radiotherapy in limited stage small cell lung cancer:
} a Dutch multicenter phase II study

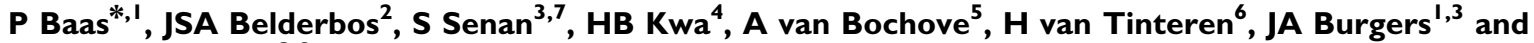 \\ JP van Meerbeeck ${ }^{3,8}$
}

'Department of Thoracic Oncology, The Netherlands Cancer Institute, Plesmanlaan 121, 1066 CX, Amsterdam, The Netherlands; ${ }^{2}$ Department of Radiation Oncology, The Netherlands Cancer Institute, Amsterdam, The Netherlands; ${ }^{3}$ Rotterdam Oncological Thoracic Study group ROTS, Rotterdam, The Netherlands; ${ }^{4}$ Department of Pulmonology, Onze Lieve Vrouwen Gasthuis, Amsterdam, The Netherlands; ${ }^{5}$ Department of Medical Oncology 'De Heel' Hospital, Zaandam, The Netherlands; ' Department of Biometrics, The Netherlands Cancer Institute, Amsterdam, The Netherlands

To improve the prognosis of limited stage small cell lung cancer (LS-SCLC) the addition of concurrent thoracic radiotherapy to a platinum-containing regimen is important. In the Netherlands, we initiated a multicenter, phase II study, of the combination of four cycles of carboplatin (AUC 5), paclitaxel $\left(200 \mathrm{mg} \mathrm{m}^{-2}\right)$ and etoposide $(2 \times 50 \mathrm{mg}$ orally for 5 days) combined with $45 \mathrm{~Gy}$ (daily fractions of $1.8 \mathrm{~Gy}$ ). The radiation was given to the involved field and concurrently with the second and third chemotherapy cycle. Patients with a partial or complete response received prophylactic cranial irradiation to a dose of 30 Gy. From January 1999 to December 200I, 37 of the 38 patients with LS-SCLC entered were eligible for toxicity analysis and response. Grade 3 and 4 haematological toxicity occurred in 57\% (21/37) with febrile neutropenia in 24\% (9/37). There were no treatment-related deaths or other grade 4 toxicity. Grade 3 toxicities were oesophagitis (27\%), radiation pneumonitis (6\%), anorexia (14\%), nausea (I6\%), dyspnea (19\%) and lethargy (22\%). The objective response rate was 92\% (95\% confidence interval (Cl) $80-98 \%)$ with a median survival time of 19.5 months $(95 \% \mathrm{Cl}$ 12.8-29.2). The I-, 2- and 5-year survival rate was 70, 47 and 27\%, respectively. In field local recurrences occurred in six patients. Distant metastases were observed in 19 patients of which 13 in the brain. This study indicates that combination chemotherapy with concurrent involved-field radiation therapy is an effective treatment for LS-SCLC. Despite PCI, the brain remained the most important site of recurrence.

British Journal of Cancer (2006) 94, 625-630. doi:I0.1038/sj.bjc.6602979 www.bjcancer.com

Published online 7 February 2006

(c) 2006 Cancer Research UK

Keywords: SCLC; limited stage; concurrent radiotherapy; involved field

Small cell lung cancer (SCLC) accounts for approximately 15-20\% of all lung cancers and first-line combination chemotherapy has led to an important improvement in response and survival. The addition of thoracic radiation therapy (TRT) and prophylactic cranial irradiation (PCI) has further improved the overall survival (Pignon et al, 1992; Warde and Payne, 1992). Despite the addition of sequential irradiation to the thorax, patients with limited stage (LS) of the disease and a good performance status do not surpass survival rates of $20 \%$ at 2 years (Johnson et al, 1990).

Besides the choice of the best available chemotherapy regimens, the optimal timing of radiation in relation to the chemotherapy has been a matter of debate for many years. There are several lines of

\footnotetext{
*Correspondence: Dr P Baas; E-mail: p.baas@nki.nl

${ }^{7}$ Current address: Department of Radiation Oncology, Free University Medical Center, Amsterdam, The Netherlands.

${ }^{8}$ Current address: Department of Pulmonology, University of Ghent, Ghent, Belgium.

Received 19 September 2005; revised 4 January 2006; accepted 5 January 2006; published online 7 February 2006
}

evidence that early (concurrent) radiation is superior to late (sequential) administered radiation therapy (Murray et al, 1993). In Europe, the combination of cyclophosphamide, doxorubicin and etoposide has been used for many years but this regimen does not allow concurrent irradiation to the thorax due to the doxorubicin related risk of cardio pulmonary toxicity (Friedman et al, 1978; Torti et al, 1986).

Recently, several new drugs have been tested for their activity against SCLC and have shown promising results (Ettinger, 2001). Paclitaxel has demonstrated promising activity in extensive disease as a single agent with a response of 34-68\% (Ettinger et al, 1995; Hainsworth and Greco, 1995) and has shown to act as a radiosensitizer (Kirkbride et al, 1997; Langer et al, 1997; Choy et al, 2000).

Carboplatin is considered to be nearly equivalent to cisplatin in efficacy in SCLC while offering the advantage of outpatient administration (Green and Seal, 1990; Skarlos et al, 1994). Like paclitaxel, carboplatin has radiosensitising properties, which makes the combination of the two drugs with radiotherapy interesting (Thomas et al, 1997).

Hainsworth et al (1997) have investigated the combination of carboplatin, paclitaxel and etoposide in a dose escalation study in 
1997. Concurrent TRT was given during cycle 3 and 4 to patients with LS (45 Gy in 25 fractions) and was considered acceptable. Based on these results, we decided to perform a multicentre, feasibility/phase II study to evaluate the toxicity and efficacy of carboplatin, paclitaxel and etoposide combined with concurrent involved field TRT (starting concurrent with the second cycle) in chemo-naive patients with LS SCLC.

\section{PATIENTS AND METHODS}

Eligible patients had biopsy or cytology proven LS SCLC. Chest $\mathrm{X}$-ray, CT scan of the chest and upper abdomen, bone scintigraphy and MRI or CT-scan of the brain were standard examinations. No prior chemotherapy or radiation was allowed. Patients had to be older than 18 years, had to have a performance status WHO grade $0-2$ and a measurable or evaluable lesion and no major organ failure, Haemoglobin $>6.0 \mathrm{mmoll}^{-1}$, WBC $>3.0 \times 10^{9} \mathrm{l}^{-1}$ and platelets $>100 \times 10^{9} 1^{-1}$, normal ASAT and ALAT $(<2.5 \times$ ULN $)$, bilirubin $(<2 \times \mathrm{ULN})$, Lactate dehydrogenase within 1.5 times ULN, serum creatinine level $<1.25$ normal or creatinine clearance $>60 \mathrm{ml} \mathrm{min}^{-1}$. Patients were exclude if there were signs of distant metastases or a weight loss of $>10 \%$ in the preceding 3 months. Before registration, the radiation oncologist had to decide whether the tumour volume allowed the delivery of concurrent TRT. All patients gave written informed consent and the ethics committee of all participating hospitals approved the study.

\section{Chemotherapy}

Patients were treated with four cycles of chemotherapy given every 3 weeks. This consisted of a three-drug combination. Paclitaxel (Bristol Myers- Squibb, Woerden, The Netherlands) was given at a dose of $200 \mathrm{mg} \mathrm{m}^{-2}$ in a $3 \mathrm{~h}$ intravenous infusion. Standard premedication consisted of dexamethasone, clemastine and ranitidine.

Carboplatin (Bristol Myers- Squibb, Woerden, The Netherlands) was given directly after administration of paclitaxel by a $30 \mathrm{~min}$ infusion. The dose was calculated using the Calvert formula (Calvert et al, 1989). Etoposide capsules (Bristol Myers- Squibb, Woerden, The Netherlands) were taken orally in a daily dose of $2 \times 50 \mathrm{mg}$ for 5 days following the infusions of carboplatin and paclitaxel. In case of vomiting, no redosing was allowed.

Dose adjustments or delays or were made when haematological toxicity occurred. Redosing was only permitted when the WBC was $>3.0 \times 10^{9} 1^{-1}$, neutrophils $>1.5 \times 10^{9} 1^{-1}$, platelets $>100 \times$ $10^{9} 1^{-1}$ and no clinical signs of infection. If these conditions were not fulfilled the blood counts were repeated after 1 week. In case of a delay of more than 2 weeks, the patient went off study.

Dose reductions were applied for nadirs (platelets $<50 \times 10^{9} 1^{-1}$; neutrophils $<0.5 \times 10^{9} 1^{-1}$ ) with $25 \%$ reduction in carboplatin dose, $15 \%$ decrease for the paclitaxel dose and a $50 \%$ decrease in daily dose of etoposide.

For any nonhaematological grade 3 toxicity (except untreated nausea, vomiting and alopecia) the treatment was delayed until recovery.

When a patient experienced neurotoxicity CTC grade 2; the dose of paclitaxel was reduced with $15 \%$ and another $10 \%$ when the neurotoxicity persisted. When, despite dose reductions, grade 2 neurotoxicity persisted, the patient went of study.

Anti-emetics were given as prophylaxis according to the local practice. The use of growth factors was not allowed but prophylactic antibiotics could be used.

\section{Thoracic radiation therapy}

A total dose of $45 \mathrm{~Gy}$ was given in 25 fractions of $1.8 \mathrm{~Gy}$ (five fractions per week) to the involved field. Thoracic radiation

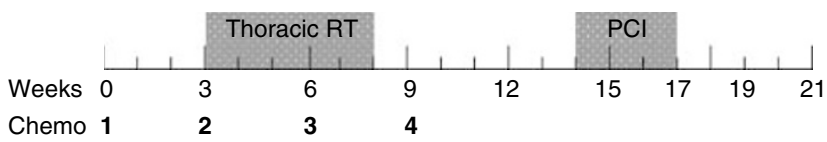

Figure I Time schedule of the four chemotherapy cycles, the radiotherapy treatment to the thorax and prophylactic cranial irradiation. The $X$-axis is in weeks. PCl: Prophylactic Cranial Irradiation.

therapy started within 1 week after the start of the second cycle of chemotherapy (Figure 1). The target volume for irradiation was the primary tumour and all clinical and radiological involved lymph nodes with a short-axis diameter of $\geqslant 1 \mathrm{~cm}$ (involved field irradiation). The mandatory radiotherapy planning CT scan, with intravenous contrast, was acquired shortly after the end of the first cycle of chemotherapy.

Megavoltage equipment was used with photon energies of 6 or $8 \mathrm{MV}$ using a multileaf collimator or standard blocks to shape the irradiation portals according to the target volume. If possible anterior - posterior fields were applied. The radiotherapy treatment was interrupted for 1 week if the platelet count fell to $\leqslant 30 \times 10^{9} 1^{-1}$ and if fewer than 20 fractions had been given. If thrombocytopenia occurred after more than 20 fractions had been given, the remaining fractions were omitted.

\section{Prophylactic cranial irradiation}

Prophylactic cranial irradiation was given to patients with a complete or partial remission, starting five weeks after the end of last course of chemotherapy. A total dose of $30 \mathrm{~Gy}$ was administered in twelve fractions of $2.5 \mathrm{~Gy}$ each (four fractions a week), or 15 fractions of $2 \mathrm{~Gy}$ (five fractions a week).

\section{Baseline and response evaluation}

Three weeks prior to the start of treatment, baseline tumour measurements were performed. This included a bronchoscopy, CT scan of the chest and upper abdomen and Chest X-ray. In all patients, a medical history, physical examination, performance status and laboratory values were assessed before start of treatment. Prior to every new cycle a medical history, weight, performance status, physical examination, complete blood count, liver and renal function tests were performed. The toxicity, occurrence of adverse effects, hospitalisations and use of concomitant medications was assessed prior to each cycle of chemotherapy. Toxicity was scored using the NCIC/CIC criteria (version 2.0, revised March 23, 1998). After completion of the treatment, patients were followed every 3 months until disease progression or death. A repeat bronchoscopy was performed in all responding patients when endobronchial tumour was observed at diagnosis. All radiological responses were confirmed by a second CT scan after 4 weeks. The time to progression was calculated from the end of treatment (excluding PCI) and the date of last follow-up or the date of disease progression, whichever happened first.

\section{Statistical analysis}

This phase II study aimed to recruit a total of 50 patients in a 3year period (EORTC, 1997). The study actually enrolled 38 patients in three years and it was decided to halt the trial because of the highly positive experience with this concurrent chemo-radiotherapy. This decision was also weighed by data from other studies (Kirschling et al, 1999; Thomas et al, 2001). Survival was analysed using a Kaplan Meier curve. 
Table I Patient characteristics

\begin{tabular}{|c|c|c|}
\hline & \multicolumn{2}{|c|}{ All } \\
\hline & $\mathbf{N}$ & $\%$ \\
\hline All & 38 & 100 \\
\hline \multicolumn{3}{|l|}{ Gender } \\
\hline Male & 22 & 58 \\
\hline Female & 16 & 42 \\
\hline Age median (range) & 65 & ( $46-82$ years) \\
\hline \multicolumn{3}{|l|}{ Smoking status } \\
\hline Never smoked & I & 3 \\
\hline Smoked previously $>10$ years ago & 6 & 16 \\
\hline Smoked previously $\leqslant 10$ years ago & 31 & 82 \\
\hline \multicolumn{3}{|l|}{ Active infection } \\
\hline No & 37 & 97 \\
\hline Documented controlled & । & 3 \\
\hline \multicolumn{3}{|l|}{ Performance status } \\
\hline 0 & 17 & 45 \\
\hline । & 19 & 50 \\
\hline 2 & 2 & 5 \\
\hline \multicolumn{3}{|l|}{ Lymph node involvement } \\
\hline Ipsilateral mediastinal nodes & 26 & 68 \\
\hline Contralateral mediastinal nodes & 7 & 18 \\
\hline Supraclavicular nodes & 5 & 13 \\
\hline
\end{tabular}

One patient did not receive protocol treatment due to uncontrolled hypertension and ECG abnormality.

\section{RESULTS}

\section{Patient characteristics}

From January 1999 until December 2001, 38 patients were enrolled from eight centres. One patient did not start treatment because of uncontrollable hypertension and ECG abnormalities and was excluded from both toxicity and response evaluation. The ratio of male to female patients was 22:16 and all other patient characteristics are presented in Table 1 . In all, $95 \%$ of patients had a performance status of 0 or 1 . In 20 patients $(52 \%)$ the primary tumour was located on the right side and there was involvement of the ipsilateral mediastinal lymph nodes in 26 patients $(68 \%)$. Contra-lateral mediastinal lymph nodes were observed in seven patients $(18 \%)$ and five patients $(13 \%)$ presented with positive supraclavicular lymph nodes. In two patients, revision of the pathology revealed another type of tumour (one large cell neuroendocrine tumour and one mixed small cell/nonsmall cell tumour). These patients, however, had already started the treatment and were include for the toxicity analyses.

\section{Dose administration and toxicity}

For the 37 patients, 141 of the planned 148 cycles of chemotherapy were given. Five patients did not receive a fourth cycle and one patient stopped treatment after the first cycle because of disease progression. Adjustments of the chemotherapy schedule occurred in $62 \%(23 / 37)$ of the patients. In 12 out of the 37 patients $(32 \%)$ a dose modification was given and in 14/37 (38\%) a dose delay occurred. There were no treatment related deaths. Patients were hospitalised because of complications (febrile neutropenia, oesophagitis) in $15 \%$ and for logistical reasons in $25 \%$ (to appropriately co-ordinate the timing between chemotherapy administration and radiotherapy). The reasons for dose modification or delay are summarised in Table 2.
Table 2 Treatment details by chemotherapy cycle

\begin{tabular}{|c|c|c|c|c|}
\hline & \multicolumn{4}{|c|}{ Cycle number } \\
\hline & $\mathbf{I}$ & 2 & 3 & 4 \\
\hline Number of cycles & 37 & 36 & 36 & 32 \\
\hline Dose modification & । & 2 & 7 & 12 \\
\hline \multicolumn{5}{|l|}{ Reasons } \\
\hline Haematological toxicity & & I & 2 & 5 \\
\hline Other toxicity & & 1 & 5 & 7 \\
\hline Dose delay & । & 3 & 13 & 14 \\
\hline \multicolumn{5}{|l|}{ Reasons } \\
\hline Hyponatraemia & । & & & \\
\hline Haematological toxicity & & 3 & II & 9 \\
\hline Other toxicity & & & 2 & 5 \\
\hline Hospitalisation & 9 & 11 & 15 & 7 \\
\hline
\end{tabular}

Table 3 Toxicity according to the CTC criteria version 2.0/revised March 1998 for 37 patients

\begin{tabular}{lrcr}
\hline & Grade 3 & Grade 4 & $\%$ \\
\hline Haematological toxicity & 3 & & \\
Anemia & 13 & 8 & 87 \\
Neutropenia & 9 & - & 24 \\
Febrile neutropenia & 5 & 3 & 14 \\
Thrombocytopenia & & & \\
Non haematological toxicity & 5 & - & 14 \\
Anorexia & 10 & - & 27 \\
Oesophagitis & 5 & - & 14 \\
Diarrhoea & 6 & - & 17 \\
Nausea & 4 & - & 11 \\
Vomiting & 6 & - & 17 \\
Infection & 1 & - & 3 \\
Fever & 8 & - & 62 \\
Lethargy & 2 & - & 19 \\
Neurotoxicity & 7 & - & 6 \\
Dyspnea & 2 & - & 8 \\
Alopecia & 2 & 14 \\
Vision & 3 & - & \\
Cardiovascular & 5 & - & \\
Other (pain, hyponatremia) & & & \\
\hline
\end{tabular}

The worst toxicity score (grade 3 and 4) per patient are presented.

The highest toxicity recorded (grade 4) was haematological. Other grade 3 toxicity was lethargy (30\%), oesophagitis (37\%), dyspnea $(26 \%)$, anorexia (19\%), nausea and infection $(22 \%)$ and vomiting (15\%). Some possibly related neurotoxicity was observed (sensory, motor, vision, all 7\%) (Table 3).

A total of 36 patients received TRT with a mean dose of 44.8 Gray. One patient was ineligible and one refused further therapy after the first cycle. Three patients missed 3 or 4 fractions due to oesophagitis complicated by fever, leucocytoand thrombocytopenia or haemorrhage. In all, 30 patients were treated with PCI with a mean dose of $28.2 \mathrm{~Gy}$. Toxicity related to the TRT was oesophagitis in $37 \%$ grade $3,34 \%$ grade 2 and $37 \%$ grade 1 . Nine patients $(37 \%)$ required medical intervention (nasogastric feeding) for grade 3 oesophagitis. Oesophagitis grade 4 was not observed. Two patients required steroid treatment and oxygen administration for a grade 3 radiation pneumonitis. 


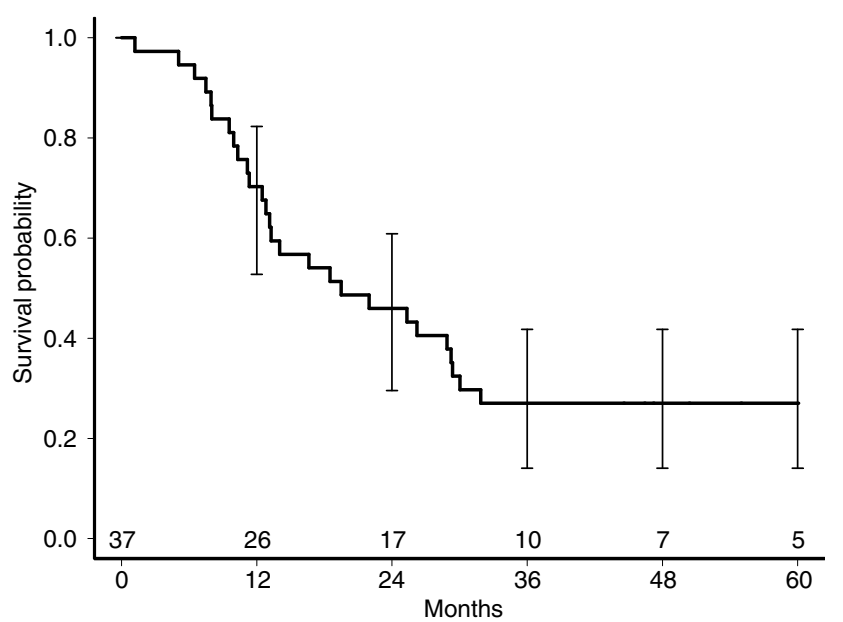

Figure 2 Kaplan-Meier survival curve. The $X$-axis shows the survival in months and the number of patients at risk. The survival probability is presented on the $Y$-axis.

\section{Response and time to progression}

An overall response of $92 \%$ ( $34 / 37$ patients) was observed. In all, 16 patients achieved a complete radiological and histological response (CR), while 18 patients showed postradiation changes on the CT scan or chest X-ray while endobronchial examination revealed no residual tumour cells (PR). In three patients the response was not evaluable because of early toxicity. Figure 2 shows the overall survival curve, with a median overall survival of 19.5 months (95\% CI 12.8-29.2 months). The 1-, 2- and 5-year survival rates were 70,46 and $27 \%$, respectively. The median time to progression (TTP) from start of chemotherapy for all patients was 15.9 months. Patients with a CR had 14.4 months TTP and for patients achieving a PR this was 23.9 months. At the time of analysis nine patients were still alive and progression-free.

Local recurrences (within the target area) were seen in six patients $(16 \%)$ while distant recurrences occurred in 19 patients (51\%). In 13 patients (35\%) the first site of distant relapse was the brain.

\section{DISCUSSION}

In this study, we have confirmed that the combination of carboplatin, paclitaxel and etoposide can be safely combined with concurrent involved field TRT. The overall response rate was $92 \%$, which is comparable to other studies (Murray et al, 1993; Laurie et al, 2004). The 2- and 5-year survival rates of 46 and $27 \%$ are promising, especially when compared to the survival data of doxorubicine containing regimens with sequential radiotherapy (Bunn et al, 1986; Giaccone et al, 1993). Other platinum-containing regimens are considered more effective, even when combined with sequential radiotherapy as shown in an overview by Laurie et al (2004). This all adds to the evidence that concurrent chemoradiation therapy should be considered standard treatment for patients with LS disease and good performance.

Overall, we observed a median TTP of 15.9 months. The difference in TTP between the patients with a PR and a CR may partly be explained by the definition of response. Owing to the concurrent use of chemotherapy and radiation to the thorax, there is an increased chance of pneumonitis and lung fibrosis, which will be visible on both chest X-ray and CT scan. This may also explain the relative high number of patients achieving a PR in our series. Turrisi (1998) reported similar data on the significance of 'partial responses' after concurrent platinum etoposide-TRT. In this intergroup study, $32 \%$ of patients were 'partial responders', and their 5 -year survival after twice-daily radiotherapy was $23 \%$ while once-daily radiotherapy resulted in a 5-year survival of $8 \%$.

This study shows that it is feasible to plan the chemotherapy and involved field TRT according to this protocol in a multicentre setting. Of all, 35 patients started the planned radiation therapy. The radiation therapy started within the first week of the second cycle, which allowed the radiation oncologist to optimally plan the radiation treatment and profit from possible tumour shrinkage after the first cycle. To prevent undesired interactions, the radiation dose on the first day of the third cycle was given before infusion of carboplatin and paclitaxel. Only three patients missed a limited number of fractions of radiation therapy due to haematological toxicity or oesophagitis. The mean total dose of radiation was $44.8 \mathrm{~Gy}$ with a significant but expected proportion of radiation oesophagitis (grade 3 ) of $37 \%$. In two patients clinical and radiological signs of radiation pneumonitis occurred, requiring the use of oral steroids and oxygen support.

It is important to note that, despite PCI, 13 of the 30 patients presented with brain metastases as first site of failure. This is certainly an unexpected observation.

This is the first study prescribing involved field irradiation for LS-SCLC. The relatively low number of in field recurrences (six patients) supports the idea that concurrent TRT, with a reduced overall treatment time, has advantages over sequential TRT for loco-regional tumour control and is safe.

Concurrent thoracic radiotherapy seems to improve survival by eliminating chemo-resistant cells early in the treatment process. Although many studies have addressed this issue, the optimal timing of the radiation is not yet elucidated (Payne et al, 1994; Erridge and Murray, 2003). Takada et al (2002) reported a phase III study comparing concurrent and sequential radiation in combination with cisplatin and etoposide. The concurrent treatment arm had superior median survival (27.2 vs 19.7 months) and 5-year survival (23.7 vs 18.3\%). Severe oesophagitis occurred more often in the concurrent treatment arm but was infrequent $(<10 \%)$. Haematological toxicity (grade $\geqslant 3$ ) was $88 \%$ in the concurrent treatment arm and $54 \%$ in the sequential arm. This reported toxicity is comparable with our findings. Toxicity was predominantly haematological and resulted in a dose delay or reduction in $63 \%$ of the patients, which is considered an important issue.

The use of colony stimulating growth factors was prohibited because of the lack of reliable data and the possible detrimental effect when used with concurrent thoracic radiation. The SWOG performed a phase III study on the use of GM-CSF with concurrent chemo-radiotherapy (Bunn et al, 1995). The combination was associated with significantly deeper white blood cell and neutrophil nadirs, a significant increase in life-threatening thrombocytopaenia, longer hospital stay, higher incidence of intravenous antibiotic use, need for more transfusions, and a greater number of toxic deaths.

Another approach is the use of hyper-fractionated schedules in LS-SCLC. The effect of twice daily irradiation $v s$ standard once daily radiation has been investigated by Turrisi et al (1999). This randomized trial compared once daily $1.8 \mathrm{~Gy}$ radiation $v s$ twice daily $1.5 \mathrm{~Gy}$ radiation therapy to a total of $45 \mathrm{~Gy}$. Both local control and survival were significantly improved in the experimental arm. The loco-regional recurrence rate dropped from 52 to $36 \%$ and at 5 -year follow-up the survival was $16 \%$ in the standard arm compared with $26 \%$ in the experimental arm. This study has now led to new studies comparing high total doses of irradiation given once daily or by hyper fractionation. One of the disadvantages of hyper-fractionation is the increased risk of severe oesophagitis.

Recently, other chemotherapy regimens have been tested in SCLC. Two Japanese groups observed improved survival in patients with extensive stage (ES) SCLC when cisplatin was combined with irinotecan (Noda et al, 2002; Han et al, 2005). A median survival of 12.8 months for this new combination 
compared to 9.4 months for cisplatin/etoposide has attracted attention and this study is one of the few that have shown such a success for chemotherapy alone. In Europe and the USA, phase III studies are now underway to determine the exact role of irinotecan/cisplatin combination in ES SCLC. The preliminary results however do not confirm the Japanese findings. In addition, the implementation of irinotecan/cisplatin with concurrent TRT is quite complicated. Irinotecan is a potent radiosensitizer $\mathrm{Wu}$ and Choy, 2002), it might, therefore, be expected that the combination of cisplatin and irinotecan with concurrent radiation therapy can lead to severe radiation induced oesophagitis and pneumonitis. So far the Japanese study by Han et al (2005) has not reported this.

The addition of a third drug in the treatment of SCLC has been questioned by at least two studies. The CALGB 9732 investigated the addition of paclitaxel to a combination of cisplatin and etoposide in patients with ES-SCLC (Neill et al, 2005). More toxic deaths (6.5 vs $2.4 \%)$ were reported in the three-arm combination and there was no improvement in overall survival. The RTOG 9606 study reported on the results of twice daily irradiation combined with paclitaxel, etoposide and cisplatin in patients with LS SCLC (Ettinger et al, 2005). In this phase II study, the radiation was given during the first cycle with a reduced dose of paclitaxel (from 175 to $135 \mathrm{mg} \mathrm{m}^{-2}$ ). The median survival of 24.7 months with a $54.7 \%$ 2 -year survival rate is in line with other reported studies (Turrisi et al, 1999 and our study). Haematological toxicity (grade 3-4) occurred in $44 \%$ and oesophagitis grade 3 in $17 \%$ and grade 4 in $2 \%$ of the 53 evaluable patients. It can be concluded that for the treatment of both LS and ES SCLC a two-drug combination is probably sufficient.

Our study demonstrates that the three-drug combination and concurrent involved field thoracic radiotherapy is feasible in a multicentre setting in the Netherlands. The results also indicate that the haematological toxicity remains the major problem. Both survival and response rate seems superior to the combination of $\mathrm{CDE}$ and sequential radiotherapy. Nowadays our attention is directed to optimising the radiation schedules, delivering higher doses to the primary tumour and involved lymph nodes and to limit the haematological toxicity by using a two-drug regimen.

\section{ACKNOWLEDGEMENTS}

We thank Dr Liesker, pulmonologist in Amsterdam; Dr van der Heijden, pulmonologist in Beverwijk; Dr Schülzer pulmonologist in Haarlem and Mr Danny Baars for data handling and processing. We thank Dr N Russel for the critical review of the manuscript. We are grateful for the support for data management by the Dutch Cancer Society. This study was supported by a grant from Bristol Meyers- Squibb for drug costs.

\section{REFERENCES}

Bunn Jr PA, Crowley J, Kelly K, Hazuka MB, Beasley K, Upchurch C, Livinston R, Weiss GR, Hicks WJ, Gandara DR (1995) Chemoradiotherapy with or without granulocyte-macrophage colony-stimulating factor in the treatment of limited-stage small-cell lung cancer: a prospective phase III randomized study of the Southwest Oncology Group. J Clin Oncol 13(7): $1632-1641$

Bunn PA, Greco FA, Einhorn L (1986) Cyclophosphamide, doxorubicin, and etoposide as first-line therapy in limited small cell lung cancer. Semin Oncol 13(3 Suppl 3): S45-S53

Calvert AH, Newell DR, Gumbrell LA, O'Reilly S, Burnell M, Boxall FE, Siddik ZH, Judson IR, Gore ME, Wiltshaw E (1989) Carboplatin dosage: prospective evaluation of a simple formula based on renal function. J Clin Oncol 7(11): 1748-1756

Choy H, Devore III RF, Hande KR, Porter LL, Rosenblatt P, Yunus F, Schlabach L, Smith C, Shyr Y, Johnson DH (2000) A phase II study of paclitaxel, carboplatin, and hyperfractionated radiation therapy for locally advanced inoperable non-small-cell lung cancer (a Vanderbilt Cancer Centre Affiliate Network Study). Int J Radiat Oncol Biol Phys 47(4): $931-937$

EORTC. Phase II trials in the EORTC (1997) The Protocol Review Committee, the Data Centre, the Research and Treatment Division, and the New Drug Development Office. European Organization for Research and Treatment of Cancer. Eur J Cancer 33(9): 1361-1363

Erridge SC, Murray N (2003) Thoracic radiotherapy for limited-stage small cell lung cancer: issues of timing, volumes, dose, and fractionation. Semin Oncol 30(1): 26-37

Ettinger DS (2001) New drugs for chemotherapy-naive patients with extensive-disease small cell lung cancer. Semin Oncol 28(2 Suppl 4): $27-29$

Ettinger DS, Berkey BA, Abrams RA, Fontanesi J, Machtay M, Duncan PJ, Curran Jr WJ, Movsas B, Byhardt RW, Radiation Therapy Oncology Group 9609 (2005) Study of Paclitaxel, Etoposide, and Cisplatin chemotherapy combined with twice-daily thoracic radiotherapy for patients with Limited Stage Small Cell Lung Cancer: a Radiation Therapy Oncology Group 9609 Phase II study. J Clin Oncol 23: 4991-4998

Ettinger DS, Finkelstein DM, Sarma RP, Johnson DH (1995) Phase II study of paclitaxel in patients with extensive-disease small-cell lung cancer: an Eastern Cooperative Oncology Group study. J Clin Oncol 13(6): $1430-1435$

Friedman MA, Bozdech MJ, Billingham ME, Rider AK (1978) Doxorubicin cardiotoxicity. Serial endomyocardial biopsies and systolic time intervals. JAMA 240(15): 1603-1606
Giaccone G, Dalesio O, McVie GJ, Kirkpatrick A, Postmus PE, Burghouts JT, Vendrik C, Roozendaal K, Planting AS, Quoix E, for the EORTC (1993) Maintenance chemotherapy in small-cell lung cancer: long-term results of a randomized trial. European Organization for Research and Treatment of Cancer Lung Cancer Cooperative Group. J Clin Oncol 11(7): $1230-1240$

Green M, Seal KHL (1990) Carboplatin in non small cell lung cancer: The Cancer and Leukemia Group B experience. Carboplatin (JM-8) Current perspectives and future directions. Philadelphia: WB Saunders Company, pp 301-306

Hainsworth JD, Gray JR, Stroup SL, Kalman LA, Patten JE, Hopkins LG, Thomas M, Greco FA (1997) Paclitaxel, carboplatin, and extendedschedule etoposide in the treatment of small-cell lung cancer: comparison of sequential phase II trials using different dose-intensities. I Clin Oncol 15(12): $3464-3470$

Hainsworth JD, Greco FA (1995) Paclitaxel in lung cancer: 1-hour infusions given alone or in combination chemotherapy. Semin Oncol 22(6 Suppl 15): $45-49$

Han JY, Cho KH, Lee DH, Kim HY, Kim EA, Lee SY, Lee JS (2005) Phase II study of irinotecan plus cisplatin induction followed by concurrent twice-daily thoracic irradiation with etoposide plus cisplatin chemotherapy for limited-disease small-cell lung cancer. J Clin Oncol 23(15): $3488-3494$

Johnson BE, Grayson J, Makuch RW, Linnoila RI, Anderson MJ, Cohen MH, Gladstein E, Minna JD, Ihde DC (1990) Ten-year survival of patients with small-cell lung cancer treated with combination chemotherapy with or without irradiation. J Clin Oncol 8(3): 396-401

Kirkbride P, Gelmon K, Eisenhauer E, Fisher B, Dulude H (1997) A phase I/ II study of paclitaxel (PACLITAXEL) and concurrent radiotherapy in advanced non-small cell lung cancer. Int J Radiat Oncol Biol Phys 39(5): $1107-1111$

Kirschling RJ, Grill JP, Marks RS, Kugler JW, Gerstner JB, Kuross SA, Michalak JC, Windschitl HE, Krewer KD, Jett JR (1999) Paclitaxel and G-CSF in previously untreated patients with extensive stage small-cell lung cancer: a phase II study of the North Central Cancer Treatment Group. Am J Clin Oncol 22(5): 517-522

Langer CJ, Movsas B, Hudes R, Schol J, Keenan E, Kilpatrick D, Yeung C, Curran W (1997) Induction paclitaxel and carboplatin followed by concurrent chemoradiotherapy in patients with unresectable, locally advanced non-small cell lung carcinoma: report of Fox Chase Cancer Centre study 94-001. Semin Oncol 24(4 Suppl 12): S12 
Laurie SA, Logan D, Markman BR, Mackay JA, Evans WK (2004) Practice guideline for the combination chemotherapy in the initial management of limited stage small-cell lung cancer. Lung Cancer 43: 223-240

Murray N, Coy P, Pater JL, Hodson I, Arnold A, Zee BC, Payne D, Kostashuk EC, Evans WK, Dixon P, Evans WK, Dixon P, Sadura A, Feld R, Levitt M, Wierzbicki R, Ayoub J, Maroun JA, Wilson K, for the National Cancer Institute of Canada Clinical trials Group (1993) Importance of timing for thoracic irradiation in the combined modality treatment of limited-stage small-cell lung cancer. The National Cancer Institute of Canada Clinical Trials Group. J Clin Oncol 11(2): 336-344

Neill HB, Herndon II JE, Miller AA, Watson DM, Sandler AB, Kelly K, Marks RS, Perry MC, Ansari RH, Otterson G, Ellerton J, Vokes EE, Green M (2005) Randomized phase III intergroup trial of etoposide and cisplatin with or without paclitaxel and granulocyte colony-stimulating factor in patients with extensive-stage small-cell lung cancer: Cancer and Leukemia Group B Trial 9732. J Clin Oncol 23(16): 3752-3759

Noda K, Nishiwaki Y, Kawahara M, Negoro S, Sugiura T, Yokoyama A, Fukuoka M, Mori K, Watanabe K, Tamura T, Yamamoto S, Saijo N, for the Japanes Clinical Oncology Group (2002) Irinotecan plus cisplatin compared with etoposide plus cisplatin for extensive small-cell lung cancer. N Engl J Med 346(2): 85-91

Payne DG, Murray N, Warde P (1994) Small cell lung carcinoma: role of thoracic irradiation and its timing in relation to chemotherapy. Bull Cancer 81(2): 119-128

Pignon JP, Arriagada R, Ihde DC, Johnson DH, Perry MC, Souhami RL, Brodin O, Joss RA, Kies MS, Lebeau B, Onoshi T, Østerlind K, Martin HN, Tattersall HN, Wagner H (1992) A meta-analysis of thoracic radiotherapy for small-cell lung cancer. N Engl J Med 327(23): $1618-1624$

Skarlos DV, Samantas E, Kosmidis P, Fountzilas G, Angelidou M, Palamidas P, Mylonakis N, Provata A, Papadakis E, Klouvas G, Theocharis D, Panousaka E, Boleti E, Sphakianoudis G, Pavlidis N (1994) Randomized comparison of etoposide-cisplatin vs. etoposidecarboplatin and irradiation in small-cell lung cancer. A Hellenic Co-operative Oncology Group study. Ann Oncol 5(7): 601-607
Takada M, Fukuoka M, Kawahara M, Sugiura T, Yokoyama A, Yokota S, Nishiwaki Y, Watanabe K, Noda K, Tamura T, Fukuda H, Saijo N (2002) Phase III study of concurrent versus sequential thoracic radiotherapy in combination with cisplatin and etoposide for limited-stage small-cell lung cancer: results of the Japan Clinical Oncology Group Study 9104. J Clin Oncol 20(14): 3054-3060

Thomas P, Castelnau O, Paillotin H, Robinet LG, Muir JF, Delaval P, Gouva S, Balmes P, Blanchon F, Perdu D, Poirier R, Pommier De Santi P, PenotRagon C, Kleisbauer JP (2001) Phase II trial of Paclitaxel and Carboplatin in metastatic Small-Cell Lung Cancer: A Groupe Francais de Pneumo-Cancerologie Study. J Clin Oncol 19: 1320-1325

Thomas P, Kleisbauer JP, Robinet G, Clavier J, Poirier R, Vernenegre A, Bonnaud F, Taytard A, Paillotin D, Pommier De Santi P, Barriere JR (1997) Carboplatin as radiosensitizer in non-small cell lung cancer after cisplatin containing chemotherapy. A phase I study of a groupe francais de pneumo-cancerologie (G.F.P.C.). Lung Cancer 18(1): 71-81

Torti FM, Bristow MM, Lum BL, Carter SK, Howes AE, Aston DA, Brown Jr BW, Hannigan Jr JF, Meyers FJ, Mitchell EP, Billingham ME (1986) Cardiotoxicity of epirubicin and doxorubicin: assessment by endomyocardial biopsy. Cancer Res 46(7): $3722-3727$

Turrisi (1998) Observations after 5 year follow-up of Intergroup trial 0096: 4 cycles of cisplatin and etoposide and concurrent $45 \mathrm{~Gy}$ thoracic radiotherapy given in daily (QD) or twice daily fractions followed by 25 Gy PCI. Survival differences and patterns of failure. pASCO abstract 1757

Turrisi III AT, Kim K, Blum R, Sause WT, Livingston RB, Komaki R, Wagner H, Aisner S, Johnson DH (1999) Twice-daily compared with once-daily thoracic radiotherapy in limited small-cell lung cancer treated concurrently with cisplatin and etoposide. $N$ Engl J Med 340(4): 265-271

Warde P, Payne D (1992) Does thoracic irradiation improve survival and local control in limited-stage small-cell carcinoma of the lung? A meta-analysis. J Clin Oncol 10(6): 890-895

Wu HG, Choy H (2002) Irinotecan in combination with radiation therapy for small-cell and non-small-cell lung cancer. (Review). Oncology 16(Suppl 9): 13-18 